\title{
Effect of 4-Fluoro-N-(4-Sulfamoylbenzyl) Benzene Sulfonamide on Acquisition and Expression of Nicotine-Induced Behavioral Sensitization and Striatal Adenosine Levels
}

This article was published in the following Dove Press journal:

Drug Design, Development and Therapy

\author{
Naeem Ur Rehman' \\ Muzaffar Abbas $\mathbb{D D}^{2}$ \\ Mariya al-Rashida ${ }^{3}$ \\ Ahmed Tokhi (D) \\ Muhammad Awais Arshid ${ }^{4}$ \\ Muhammad Sona Khan' \\ Izhar Ahmad' \\ Khalid Rauf(D) \\ 'Department of Pharmacy, COMSATS \\ University Islamabad, Abbottabad \\ Campus, Islamabad, Pakistan; \\ ${ }^{2}$ Department of Pharmacy, Capital \\ University of Science and Technology \\ (CUST), Islamabad, Pakistan; \\ ${ }^{3}$ Department of Chemistry, Forman \\ Christian College (A Chartered \\ University), Lahore 54600, Pakistan; ${ }^{4}$ Aga \\ Khan University, Karachi, Pakistan
}

Correspondence: Khalid Rauf

Tel +923459824468

Email khalidrauf@cuiatd.edu.pk
Introduction: Behavioral sensitization is a phenomenon that develops from intermittent exposure to nicotine and other psychostimulants, which often leads to heightened locomotor activity and then relapse. Sulfonamides that act as carbonic anhydrase inhibitors have a documented role in enhancing dopaminergic tone and normalizing neuroplasticity by stabilizing glutamate release.

Objective: The aim of the current study was to explore synthetic sulfonamides derivative 4-fluoro-N-(4-sulfamoylbenzyl) benzene-sulfonamide (4-FBS) (with documented carbonic anhydrase inhibitory activity) on acquisition and expression of nicotine-induced behavioral sensitization.

Methods: In the acquisition phase, selected 5 groups of mice were exposed to saline or nicotine $0.5 \mathrm{mg} / \mathrm{kg}$ intraperitoneal (i.p) for 7 consecutive days. Selected 3 groups were administered with 4-FBS 20, 40, and $60 \mathrm{mg} / \mathrm{kg}$ p.o. along with nicotine. After 3 days of the drug-free period, ie, day 11, a challenge dose of nicotine was injected to all groups except saline and locomotor activity was recorded for 30 minutes. In the expression phase, mice were exposed to saline and nicotine only $0.5 \mathrm{mg} / \mathrm{kg}$ i.p for 7 consecutive days. After 3 days of the drug-free period, ie, day 11,4 -FBS at 20,40 , and $60 \mathrm{mg} / \mathrm{kg}$ were administered to the selected groups, one hour after drug a nicotine challenge dose was administered, and locomotion was recorded. At the end of behavioral experiments, all animals were decapitated and the striatum was excised and screened for changes in adenosine levels, using HPLC-UV.

Results: Taken together, our findings showed that 4-FBS in all 3 doses, in both sets of experiments significantly attenuated nicotine-induced behavioral sensitization in mice. Additionally, 4-FBS at $60 \mathrm{mg} / \mathrm{kg}$ significantly lowered the adenosine level in the striatum.

Conclusion: The behavioral and adenosine modulation is promising, and more receptors level studies are warranted to explore the exact mechanism of action of 4-FBS.

Keywords: 4-fluoro-N-(4-sulfamoylbenzyl) benzene-sulfonamide (4-FBS), nicotine sensitization, pharmacotherapy, drug addiction, locomotor activity, adenosine, HPLC

\section{Introduction}

Tobacco is a widely abused substance, and its long-term use is associated with numerous diseases that can lead to death. According to the World Health Organization (WHO), about 1.1 billion people consume tobacco chronically worldwide and an estimated six million people die each year due to tobacco abuse. ${ }^{1}$ Nicotine is the main active ingredient in tobacco that is responsible for its addictive nature. ${ }^{2}$ Chronic-intermittent 
nicotine consumption provides the basis for behavioral sensitization that is physically measured by an increase in locomotor activity in mice. More than $60 \%$ of tobacco users relapse between 3 and 12 months of abstinence period ${ }^{3,4}$ and one of the major contributors to relapse is sensitization. ${ }^{5}$ Attenuation of nicotine-induced behavioral sensitization is an important aspect of addiction therapy, and its actions including reinforcing and sensitizing effects are mediated via nicotinic acetylcholine receptors (nAChRs). ${ }^{6}$ In experimental animals, repeated nicotine administration increases dopamine levels in the striatum, a part of the limbic system associated with voluntary movements. ${ }^{7}$ Nicotine produces dynamic changes in the total number of nAChRs in these areas, resulting in the alteration of the dopamine system and subsequent behavioral effects. ${ }^{8}$ Supporting this, it has been shown that dopamine D1 receptor antagonist (SCH-23390) administration can lead to reduced sensitization produced by cocaine, methamphetamine, and nicotine. ${ }^{9}$ The therapeutic success associated with the use of nicotinic receptor-based medications is not so promising and there is a need to look for therapies with diverse targets. $^{10}$

Mechanistically nicotine addiction is a complex interplay and cross-talk between dopamine and many other neuromodulators, like adenosine that plays an important role in nicotine sensitization and dependence. ${ }^{11}$ Adenosine, an omnipresent neuromodulator exerts its effects by activating G-protein coupled receptors, namely (A1, A2A, A2B, and A3) receptors. Among them, adenosine A1, A2A receptors have gained considerable scientific interest as potential modulators of the effects of nicotine, both because of their predominant localization in brain circuitries that are involved in reinforcement, ${ }^{12,13}$ and have been reported to affect D1 and D 2 receptors responses also. ${ }^{14}$ Adenosine levels are altered following acute or chronic use of various Psychostimulants, like amphetamine, cocaine, alcohol, and nicotine. ${ }^{13-17}$ This alteration is because of D1 receptor activation which is positively coupled to adenylate cyclase and causes an increase in cAMP, ${ }^{13}$, and upon its breakdown, the level of adenosine rises both inside and outside the cell. Extracellular adenosine levels rise up-to 100 times under pathological conditions. ${ }^{18,19}$ Adenosine and adenosine receptors primarily $\mathrm{A} 2 \mathrm{~A}$ are generally extensively reported to have a key role in psychostimulants addiction $^{11}$ and have been recently reported to have a major role in both acquisition and expression of nicotine-induced behavioral sensitization as discussed by. ${ }^{20}$ There is ample evidence of anatomic, structural, and functional interaction between adenosine and dopamine receptors in $\mathrm{CNS},{ }^{14}$ but effects of nicotine on adenosine levels in nicotine sensitization have not yet been explored. In the last decade search for the treatment of nicotine-induced sensitization has led to the discovery of significant effects of ascorbic acid, clozapine, and mirtazapine in animal models. ${ }^{21-24}$ Furthermore, zonisamide (a sulfonamide) is shown to enhance dopaminergic tone, act as a monoamine oxidase B inhibitor and normalize neuroplasticity by stabilizing glutamate release, which together with dopamine mediates the acquisition of nicotine dependence and withdrawal. $^{25-27}$

Sulfonamide derivatives have antibacterial, diuretic, ${ }^{28}$ carbonic anhydrase inhibitory, anticonvulsant, ${ }^{29}$ antioncogenic, ${ }^{30}$ hepatoprotective, and $\mathrm{GABA}_{\mathrm{A}}$ modulating activity. ${ }^{31}$ Various sulfonamides have been reported in multiple neurological disorders including alcohol and nicotine dependence. A pilot clinical study for smoking cessation showed that Zonisamide (a sulfonamide derivative) decreased nicotine withdrawal and craving. ${ }^{32}$ Additionally, sulphonamides have NMDA receptors antagonist effect $^{33}$ and NMDA receptor antagonists reverse nicotine sensitization. ${ }^{34}$ Keeping in view the diverse potential of sulfonamides, this study was designed to explore the potential of sulfonamide derivative, 4-FBS, carbonic anhydrase, and alkaline phosphatase inhibitor, in nicotine-induced behavioral sensitization.

\section{Materials and Methods}

\section{Animals Grouping}

Male ( $\mathrm{n}=6$ /group) BALB/c mice having weighed 25-30 $\mathrm{g}$ were obtained from the National Institute of Health Islamabad, and kept in the animal house facility at COMSATS University Islamabad, Abbottabad Campus. Animals were divided into 5 groups including saline, nicotine only and nicotine + 4-FBS at $20 \mathrm{mg}$, nicotine + 4-FBS $40 \mathrm{mg}$ / $\mathrm{kg}$, and nicotine $+4 \mathrm{FBS} 60 \mathrm{mg} / \mathrm{kg}$ grouped in Plexiglas cages and maintained at $25 \pm 1{ }^{\circ} \mathrm{C}$ with $12 \mathrm{~h} \mathrm{light/dark} \mathrm{cycle} \mathrm{and} \mathrm{free}$ access to food and water. The procedures were performed under the guidelines of the "Ethical Care Committee for Animal Research" at the CUI, Abbottabad, under the registration number PHM.Eth/cs-M04/11-34, which conformed to the guidelines of the "Animals Scientific Procedure Act (1986) UK”.

\section{Sample Preparation}

At the end of experiments, mice were sacrificed by decapitation, the whole-brain was excised onto an ice-chilled plate, the striatum was separated, weighed precisely, and 
stored at $-80^{\circ} \mathrm{C} .{ }^{35}$ For analysis, tissue was homogenized with a Teflon-glass homogenizer (Ultra-Turax ${ }^{\circledR} \mathrm{T}-50$ ) at $5000 \mathrm{rpm}$ in $0.2 \%$ ice-cold perchloric acid. The sample was centrifuged at $12,000 \mathrm{~g} / \mathrm{min}\left(4^{\circ} \mathrm{C}\right)$ (DLAB Scientific) and filtered through a $0.45 \mathrm{~mm}$ filter (CNW technologies). After that, the sample was placed in an auto-sampler for HPLC analysis.

\section{Chromatographic Conditions}

Chromatography was performed using waters Alliance 2690 separation module with PDA, UV detector, and auto-sampler (USA), following ${ }^{36}$ method for the quantification of adenosine. A C18 stainless steel column $(250 \times 4.6 \mathrm{~mm})$ (waters $X$ Select ${ }^{\circledR}$ HSS Ireland) $5 \mu \mathrm{m}$ particle size was used. The mobile phase consisted of acetonitrile and $0.01 \mathrm{M}$ monobasic sodium phosphate $(5: 95, \mathrm{v} / \mathrm{v})$; detection was performed at 260 $\mathrm{nm}$ as isocratic elution of phosphate buffer. The flow rate was $1 \mathrm{~mL} / \mathrm{min}$.

\section{Standard Preparation}

To prepare the standard for the calibration curve, a stock solution of adenosine was prepared with a concentration of $1 \mathrm{mg} / 10 \mathrm{~mL}$. This solution was diluted with distilled water to yield 100,200, 300,400,500 ng/mL. The sample was placed in an auto-sampler and a $20 \mu \mathrm{L}$ sample was set for injection in the software (Empower ${ }^{\mathrm{TM}}$ ) and the calibration curve was constructed by plotting the peak area of adenosine (y) against the concentration of adenosine $(\mathrm{x})$, using linear regression analysis. Unknown concentrations of adenosine were quantified by relating the respective peak area.

\section{Drugs and Chemicals}

Nicotine (Scharlau Laboratory, Spain) was dissolved in $0.9 \%$ normal saline, whereas 4-fluoro-N-(4-sulfamoylbenzyl) benzene-sulfonamide was provided by Dr. Mariya Al Rashida, ${ }^{37}$ that was prepared as a suspension using 5\% dimethyl sulfoxide (DMSO). The solutions and suspensions were freshly prepared daily. Nicotine was administered at a dose of $0.5 \mathrm{mg} / \mathrm{kg} /$ day intraperitoneally (i.p.), while4-FBS suspensions were administered orally in three doses $(20,40$, and $60 \mathrm{mg} / \mathrm{kg}$ ). Mice received all the doses at $10 \mathrm{~mL} / \mathrm{kg}$. $5 \%$ DMSO was administered p.o.to saline and nicotine group to ascertain that neither p.o. administration nor 5\% DMSO influence the results.

\section{Materials for HPLC Analysis}

High-performance liquid chromatography (HPLC) grade acetonitrile, water, adenosine, and monobasic sodium phosphate were purchased from the Merck local distributor in Abbottabad Pakistan.

\section{Behavioral Sensitization Procedure Apparatus}

Locomotor activity monitoring boxes measuring $(45.6 \times$ $45.6 \times 30 \mathrm{~cm}$ ) with floor line marking was used to assess nicotine-induced behavioral sensitization, which was divided internally into quadrants $(22.8 \times 22.8)$. All the boxes were cleaned with $70 \%$ ethanol before performing each activity. The recording was performed using the CAT I camera installed $300 \mathrm{~cm}$ above the locomotor boxes. The number of lines crossed per 30 min was recorded for each animal.

\section{Induction of Behavioral Sensitization by Nicotine (Model Development)}

Mice were brought to the experimental laboratory and given 30 minutes $(\mathrm{min})$ for acclimatization before the start of the experiment. They were then injected with normal saline to acquaint them with handling and other procedural-induced stresses. On test day 1, animals were again acclimatized before experiment and group $1 \quad(n=6)$ was injected normal saline whereas, group $2 \quad(n=6)$ received $0.5 \mathrm{mg} / \mathrm{kg}$ nicotine i.p. for seven days and locomotor activity (number of lines crossed) was recorded immediately for $30 \mathrm{~min}$ on day 1 and day 7 only. Following a nicotine-free period of three days, ie, on day 11 , a challenge dose was administered to the nicotine and saline-treated group, and subsequent locomotor activity was recorded. $^{22,38,39}$

\section{Effect of 4-FBS on the Acquisition of Nicotine-Induced Behavioral Sensitization}

In this set of experiment, group 1 received saline (i.p.) and 5\% DMSO (p.o.) and group 2 received nicotine (i.p.) and $5 \%$ DMSO (p.o), while group 3, 4, $5(\mathrm{n}=6)$ received $0.5 \mathrm{mg} / \mathrm{kg}$ nicotine i.p. daily along with 4-FBS, 20, 40, and $60 \mathrm{mg} / \mathrm{kg}$ orally for seven consecutive days. After nicotine injection, locomotor activity was recorded for 30 min on days 1 and 7. Following three days of abstinence period on day 11, all groups except the saline group received a challenge dose of nicotine $0.5 \mathrm{mg} / \mathrm{kg}$, and locomotor activity was recorded for $30 \mathrm{~min}^{22,38,39}$

\section{Effect of 4-FBS on the Expression of Nicotine-Induced Behavioral Sensitization}

In this set of experiments, groups 2, 3, 4, 5 were treated with nicotine $0.5 \mathrm{mg} / \mathrm{kg}$ i.p. for seven consecutive days, and locomotor activity was recorded on day 1 and day 7 for 30 
minutes. After three days of abstinence period, on day 11, groups 1 and 2 received 5\% DMSO p.o. while groups 3, 4, 5 were treated with 4-FBS, 20, 40, and $60 \mathrm{mg} / \mathrm{kg}$ p.o. A nicotine challenge dose, ie, $0.5 \mathrm{mg} / \mathrm{kg}$ was injected to all the treated groups (groups 2, 3, 4, 5) after $60 \mathrm{~min}$ and immediately locomotor activity was recorded for $30 \mathrm{~min}$. $2,38,39$

\section{Statistics}

Graph Pad Prism-8 was used for statistical analysis. Data were expressed as mean \pm SEM for a 30 min recording. For induction of behavioral sensitization, one-way ANOVA followed by Tukey's test as post hoc analysis was applied for days 1, 7, and 11. Development and expression of sensitization were evaluated by one-way ANOVA, followed by Tukey's test as post hoc analysis. A significance level of $\mathrm{p}<0.05$ was retained for data analysis.

\section{Results}

\section{Effect of Nicotine on Behavioral Locomotor Sensitization (Model Development)}

As shown in Figure 1 significant difference was observed between the nicotine and saline groups on day 7. After 3 days of abstinence period, ie, day 11 , a challenge dose of nicotine produced a heightened locomotor response compared to the saline group revealed induction of sensitization. One-way ANOVA followed by Tukey's test revealed that sensitization was developed in the nicotine group on day $7 * * \mathrm{p}<0.01$ and day $11(\mathrm{~F}(5,30)=22.00 * * *$ and $\mathrm{p}<0.001)$. Each column represents mean \pm SEM.
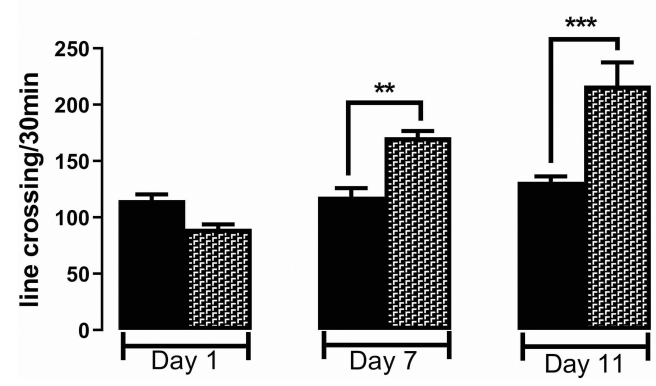

Figure I Effect of nicotine administration $(0.5 \mathrm{mg} / \mathrm{kg}$ i.p.) on the induction of behavioral sensitization. BALB/c mice ( $n=6 /$ group) were used for a seven days protocol with a nicotine challenge dose on day II. One-way ANOVA followed by Tukey's test revealed a significant difference ${ }^{* *} \mathrm{p}<0.0 \mathrm{I}$, ${ }^{* * *} \mathrm{p}<0.00 \mathrm{I}$, on days 7 and II between normal saline and nicotine-treated groups, which confirmed the development of the behavioral sensitization model group.

\section{Effect of 4-FBS on the Acquisition of Nicotine-Induced Behavioral Sensitization}

As shown in Figure 2, no significant difference was observed among all groups on day 1. One-way ANOVA followed by Tukey's test revealed that administration of nicotine increase locomotion in comparison to saline and 4-FBS at 20 and $60 \mathrm{mg} / \mathrm{kg}$ reduced locomotion but statistically not significant while 4-FBS at $40 \mathrm{mg} / \mathrm{kg}$ on day 7 shows a significant reduction (Figure $2 \mathrm{~F}(4,25)=2.499$ and $* \mathrm{p}<0.05)$ in locomotion as compared to nicotine treated group. Similarly on day 11, oneway ANOAV followed by Tukey's test revealed that there is a significant increase in locomotion between saline and nicotine $* * \mathrm{p}<0.01$ while 4 -FBS at 20,40 , and $60 \mathrm{mg} / \mathrm{kg}$ showed a significant reduction in locomotion compared to nicotine treated group (Figure $2 \mathrm{~F}(4,25)=8.211$ and $* * \mathrm{p}<0.01$, *** $\mathrm{p}<0.001)$. Each column represents mean $\pm \mathrm{SEM}$.

\section{Effect of 4-FBS on the Expression of Nicotine-Induced Behavioral Sensitization}

Repeated injection of nicotine $0.5 \mathrm{mg} / \mathrm{kg}$ for 7 consecutive days produced significant heightened locomotor response $* * p<0.01$ Figure 3 as compared to saline. Similarly on day 11, one-way ANOVA followed by Tukey's test revealed a significant difference in locomotion between saline and nicotine treated groups $* * \mathrm{p}<0.01$, while 4 -FBS at 40 and $60 \mathrm{mg} / \mathrm{kg}$ on day 11 significantly (Figure $3 \mathrm{~F}(4,25)=$ 8.195 and $* * p<0.01, * * * p<0.001)$ reverse nicotine-induced behavioral sensitization compared to nicotine treated group. Each column represents mean \pm SEM.

\section{Effect of Nicotine and 4-FBS on Adenosine Levels in Mouse Striatum (Expression Phase)}

Administration of nicotine $(0.5 \mathrm{mg} / \mathrm{kg})$ caused a significant increase in adenosine (Figure 4: $\mathrm{F}(4,25)=8.876 * *^{*} \mathrm{p}<0.01$ ) compared to saline group. 4-FBS at all doses $(20,40,60 \mathrm{mg})$ did not show any statistically significant effect in comparison to the nicotine group. One-way ANOVA followed by Tukey's multiple comparison tests was used for this analysis. As $4-\mathrm{FBS}$ at 20,40 , and $60 \mathrm{mg} / \mathrm{kg}$ do not reduce adenosine levels therefore no significant difference was observed between saline and 4-FBS at all doses.

\section{Effect of Nicotine and 4-FBS on Adenosine Levels in Mouse Striatum (Acquisition Phase)} Administration of nicotine $(0.5 \mathrm{mg} / \mathrm{kg})$ significantly increase adenosine (Figure 5: F $(4,25)=20.64$ 


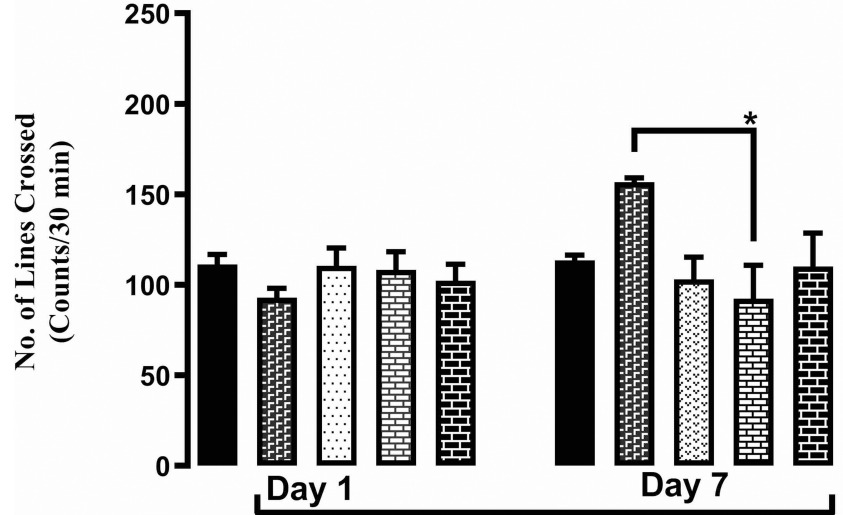

Nicotine + 4-FBS

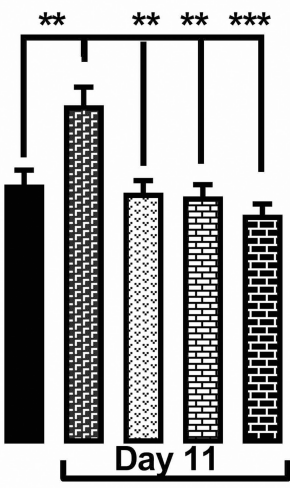

Nicotine challange dose

Figure 2 Effect of 4-FBS 20, 40,60mg/kg p.o. on the acquisition of nicotine-induced behavioral sensitization. BALB/c mice (n=6/group) were used in this protocol. On day I, one-way ANOVA followed by Tukey's test showed no significance between nicotine and 4-FBS-treated groups while on day 7 , only $40 \mathrm{mg} / \mathrm{kg}$ showed significant result * $<$ 0.05 compared to nicotine. After 3 days of abstinence, all three doses, ie, $20,40,60 \mathrm{mg} / \mathrm{kg}$ showed significant reduction in locomotion $* * \mathrm{p}<0.0 \mathrm{I}$, $* * * \mathrm{P}<0.00 \mathrm{I}$ compared to nicotine. No significant difference was observed between saline and 4-FBS 20,40 and, $60 \mathrm{mg} / \mathrm{kg}$ on days 7 and II.
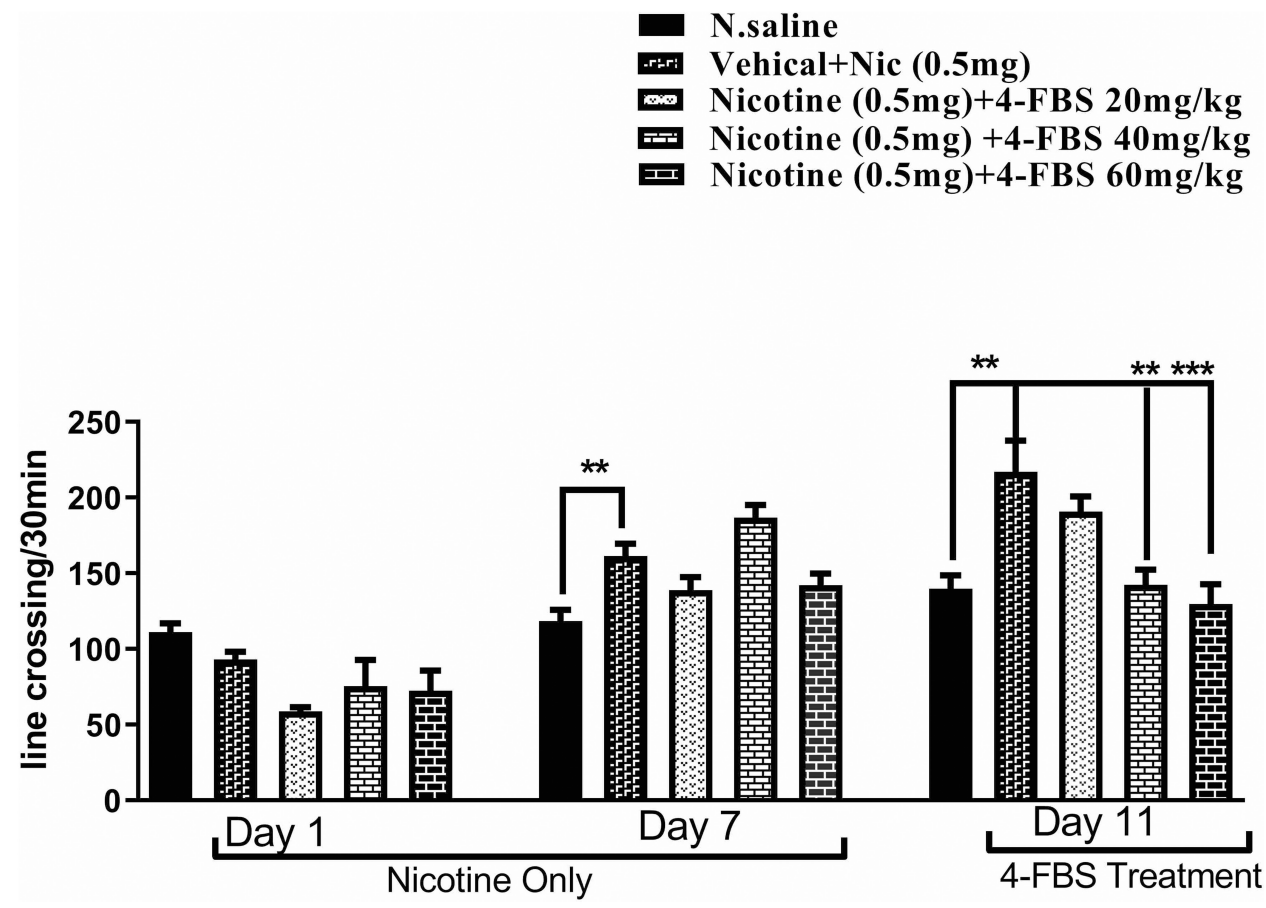

Figure 3 Effect of 4-FBS 20,40,60mg/kg p.o administration on the expression of nicotine-induced behavioral sensitization. BALB/c mice ( $\mathrm{n}=6 / \mathrm{group}$ ) were used in seven days protocol followed by a nicotine challenge dose on day II. One-way ANOVA followed by Tukey's test on day II showed that 4-FBS 40mg and 60mg have significant $* * p<0.01 * * * p<0.001$ reductions in locomotion as compared to nicotine. No significant difference was observed between saline and $4-\mathrm{FBS} 20,40$ and, $60 \mathrm{mg} / \mathrm{kg}$ on day II.

$* * * \mathrm{p}<0.001)$ compared to saline group. One-way ANOVA followed by Tukey's test revealed that 4-FBS at $60 \mathrm{mg} / \mathrm{kg}$ significantly decreased $(* \mathrm{p}<0.5)$ nicotine-induced upsurge in adenosine level. Moreover, a trend towards a decrease of adenosine level was observed in 4 -FBS $40 \mathrm{mg} / \mathrm{kg}$ but having no difference statistically. 4-FBS at 20 and $40 \mathrm{mg} /$ 

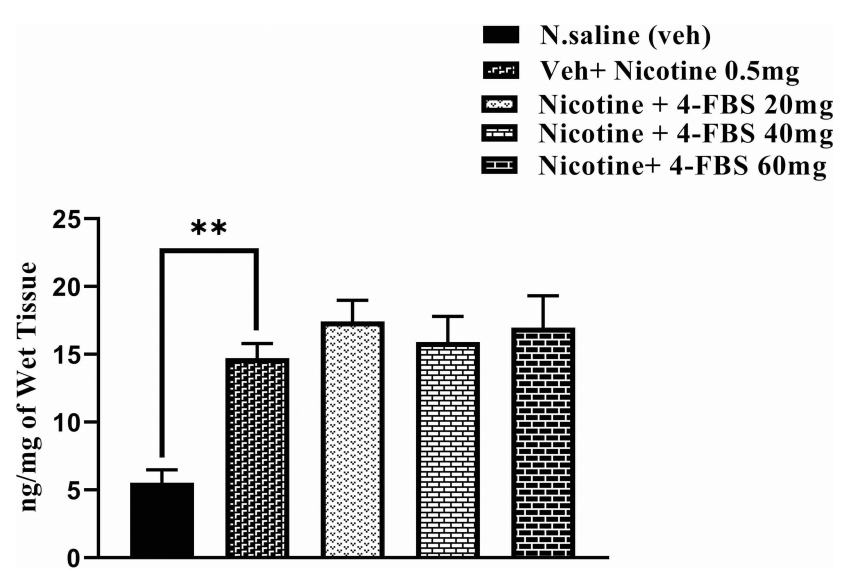

Figure 4 Effect of nicotine sensitization on Adenosine turnover in the striatum. BALB/c mice ( $n=6 /$ group) striatum were used for this protocol. Adenosine levels were significantly increased $(* * p<001)$ in the nicotine group in comparison to the saline group. No significant difference was observed between 4-FBS at 20,40, and $60 \mathrm{mg} / \mathrm{kg}$ and nicotine treated group. One-way ANOVA followed by Tukey's multiple comparison tests was used for this analysis.

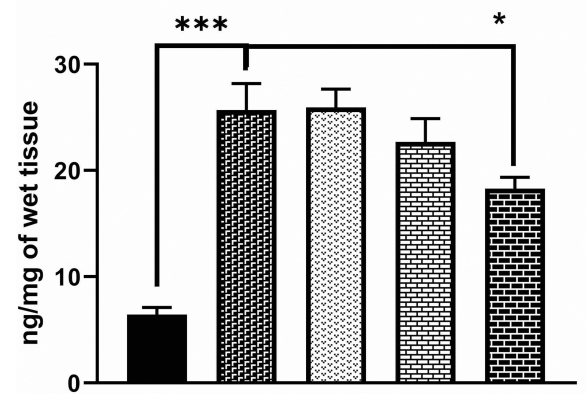

Figure 5 Effect of nicotine sensitization and 4-FBS on Adenosine turnover in the striatum. $B A L B / c$ mice ( $n=6 /$ group) striatum were used for this protocol. Adenosine levels were significantly increased $(* * * p<0.001)$ in the nicotine group compared to the saline group. 4-FBS at the dose of $60 \mathrm{mg} / \mathrm{kg}$ significantly reduces adenosine $\left({ }^{*} \mathrm{p}<0.05\right)$. Other doses $\left.20,40, \mathrm{mg} / \mathrm{kg}\right)$ have no significant difference over nicotine treated group. One-way ANOVA followed by Tukey's multiple comparison tests was used for this analysis.

$\mathrm{kg}$ did not reduce adenosine levels therefore no significant difference was observed between saline and 4-FBS.

\section{Discussion}

Various studies reported that repeated exposure to nicotine produces behavioral sensitization, while a challenge dose of nicotine produces a heightened response in locomotion after a drug-free period. ${ }^{21-24}$ Behavioral sensitization is comprised of two phases, acquisition, and expression. The acquisition is commonly associated with VTA and expression is linked with nucleus accumbens activity, which shows the long-term effect of sensitization. ${ }^{40}$

As shown in Figure 1, a 7-day administration of nicotine resulted in a gradual increase of locomotor activity and a challenge dose of nicotine produced a heightened locomotor response in comparison to saline. Similar results were reported by, ${ }^{21-24}$ in which repeated exposure to psychostimulants including nicotine produced behavioral sensitization. Locomotor suppression was recorded on day 1 that is believed to be an activation of nicotinic acetylcholine receptors on GABAergic neurons. ${ }^{41}$ Repeated administration of nicotine produces tolerance to its sedative effect reducing GABAergic tone and releases dopamine in the striatum with subsequent hyperlocomotion. ${ }^{41}$

In the acquisition phase (Figure 2) daily oral administration of 4-FBS significantly attenuated the development of nicotine-induced behavioral sensitization. On day 7, all three doses markedly reduced locomotion, but statistically, $40 \mathrm{mg} / \mathrm{kg}$ showed a significant reduction using one-way ANOVA, application of $t$-test may show significant results individually for all three doses. Similarly, a challenge dose of nicotine on day 11 failed to enhance the locomotor effect of pre administered 4-FBS treated groups in all 3 doses (Figure 2). Concomitant doses of 4FBS, along with nicotine failed to show any stimulant or sedative effect in sub-acute studies, so, it can be implied that inhibition of sensitization by 4-FBS is not because of its intrinsic sedative effect and has some other pharmacological target in the mesocorticolimbic system. ${ }^{40}$ In-silico studies demonstrate that 4-FBS is a D1 receptor antagonist (Figures S1, and S2, Table S1) and it has been documented that sensitization produced by repeated administration of cocaine, methamphetamine, and nicotine can be attenuated by the administration of D1 receptor antagonist (SCH-23390), ${ }^{9}$ thus the role of D1 receptor, in the effects of 4-FBS can be considered in nicotine-induced behavioral sensitization, although more specific studies are warranted using D1 agonists/antagonists, models. ${ }^{9}$

In the expression phase (Figure 3) nicotine-induced hyperlocomotion was significantly attenuated by acute administration of 4-FBS at 40 and $60 \mathrm{mg} / \mathrm{kg}$. Hyperlocomotion to nicotine is facilitated by the activation of postsynaptic D1 like receptors, this activation resulted in a reduction of GABAergic and glutamatergic tone, ${ }^{41-44}$, and administration of D1 receptor antagonist SCH-23390 prevent these effects. ${ }^{43,45}$ So possibly the hypo-locomotor activity observed by 4-FBS is due to this antagonistic effect on the D1 receptor which enhances GABAergic tone on 
acute doses and tolerance may develop after repeated administration evident from sub-acute studies (Figure 2). ${ }^{43}$ Our results are in accordance with one other study who claimed that systemic administration of D1 receptor blocker SCH23390 attenuates the expression of psychostimulants sensitization. ${ }^{46}$ This hypothesis is further strengthened by our in-silico study (Figures S1, and S2, Table S1) where 4-FBS interacted as a D1 receptor antagonist. Additionally, carbonic anhydrase has been reported to boost GABAergic neurotransmission both centrally and peripherally and GABA directly affects $\alpha 7^{*}$ and $\beta 2 *$ nicotinic receptors that mediate reinforcing effects of nicotine. ${ }^{31,47,48}$ Recently a structural analog of 4-FBS has been documented to enhance GABAA receptor expression, a decrease of glutamatergic GluN2A/2B receptors, and increase the expression of Fos, a marker of neuronal activation in the ventral hippocampus in ethanol dependent rats. $^{33}$ As 4-FBS is a documented carbonic anhydrase inhibitor, its interaction and subsequent enhancement of GABA can be predicted although specific receptors levels studies are needed to ascertain the effects.

Various studies show that upon acute or chronic consumption of psychostimulants, the level of adenosine is increased. ${ }^{11,13,16,49}$ This increase is due to the activation of striatal circuits to maintain homeostasis upon the consumption of ATP. ${ }^{50}$ There is a positive correlation between striatal dopamine and Adenosine, and drugs that cause an enhanced release of dopamine in striatum leads to increased levels of adenosine in the striatum. ${ }^{51}$ The adenosine receptor's role in nicotine addiction has recently attracted great scientific interest and ample studies validate the role of A2A receptors in nicotine sensitization. Similarly, addiction and transgenic mice without $\mathrm{A} 2 \mathrm{~A}$ receptors do not respond to the rewarding effects of nicotine. ${ }^{11,52}$ Moreover, A2A agonists have been reported to reverse nicotine sensitization in mice, ${ }^{20}$, and drugs that lower striatal adenosine through A2A agonism, lower the rewarding effects of nicotine and have a potential role in the treatment of nicotine addiction. ${ }^{11,53}$ Our results show that continuous treatments with nicotine $0.5 \mathrm{mg} / \mathrm{kg}$ for seven consecutive days increase adenosine in the striatum compared to the saline-treated group. Like other psychostimulants, nicotine is a dopamine (DA) agonist in the mesocorticolimbic circuitry, specifically in the ventral tegmental area and nucleus accumbens. ${ }^{16}$ This activation of dopamine particularly D1 receptors increase the production of cAMP, enhances synaptic activation of $\mathrm{NMDA}^{54}$ receptors resulting in elevated adenosine extracellularly. ${ }^{55,56}$ Excess amounts of NMDA and glutamate cause neurodegeneration or brain damage and in response, a high amount of adenosine levels are released to maintain homeostasis. ${ }^{19} 4$-FBS at acute doses, ie, $20,40,60 \mathrm{mg} / \mathrm{kg}$ did not produce any significant effect on adenosine levels in comparison to nicotine. This effect might be due to single-dose administered on the expression day (day 11).

In the acquisition phase as shown in Figure 5 nicotine treatment significantly upsurge adenosine in the striatum compared to saline-treated animals as earlier described in acute studies. This elevation of extracellular adenosine upon nicotine administration could be the result of neuronal activity on D1 receptors. ${ }^{15}$ Similar other psychostimulants studies by ${ }^{56}$ on guinea-pig and by ${ }^{15}$ on rats showed that repeated treatment with cocaine increase adenosine level, when compared to saline, treated animals. 4-FBS at $60 \mathrm{mg} / \mathrm{kg}$ for seven days reduced the adenosine level in striatum significantly in comparison to the nicotine treated group (Figure 5). In-silico studies show that 4-FBS is a D1 receptor antagonist (Figures S1, and S2, Table S1) and D1 receptor antagonist antagonize adenosine receptors, also ${ }^{14}$ because of its antagonistic interactions between A1 and D1 receptors that act as a neuroprotective on dopaminergic neuronal population. Additionally, dopaminergic receptors in the rat striatum are co-localized on the same neuron with adenosine receptors. ${ }^{57}$ Since similar distribution and density of both adenosine A1 and dopamine D1 receptors are present in basal ganglia, ${ }^{58}$ nucleus accumbens ${ }^{59,60}$ and striatum. ${ }^{61}$ There is strong evidence of antagonistic interactions between A1 and D1 receptors in the basal ganglia, ${ }^{58}$ so activation of the A1 receptor decreases the affinity of the D1 receptor and induces the uncoupling of D1 receptor from its $\mathrm{G}$ protein. ${ }^{62} \mathrm{~A} 1$ receptor activation has a primary role in control the spreading of neurodegeneration which causes neuroprotection and attenuates brain damage. $^{63-65}$

$4-F B S$ at $60 \mathrm{mg} / \mathrm{kg}$ in sub-acute studies showed a similar effect when administered before nicotine injection (Figure 5). Hence, it is predicted that D1 antagonism inversely causes A1 activation and our results show that $4-\mathrm{FBS}$ at $60 \mathrm{mg} / \mathrm{kg}$ significantly lowered adenosine, as discussed earlier drug-induced changes in striatal dopamine and serotonin is similar. ${ }^{14,53}$ Following these results, it is evident that the central reward process and effect of drug of abuse are modulated with adenosine receptors $A_{1}$ and $\mathrm{A}_{2 \mathrm{~A}} \cdot{ }^{16} \mathrm{~A}$ small number of studies are present to support the role of psychostimulants on adenosine expression and this is the first study in which the role of nicotine sensitization on adenosine was studied. 
Moreover, various studies on rats and mice conducted by ${ }^{16,49,66}$ found that the acute locomotor effect of cocaine, nicotine, amphetamine, and expression and development of nicotine sensitization is attenuated by $\mathrm{A}_{2 \mathrm{~A}}$ receptor agonists (CGS 21680) and enhanced by $A_{2 A}$ receptor antagonists (KW 6002 and DMPX). ${ }^{20}$

In the present study 4-FBS at $60 \mathrm{mg} / \mathrm{kg}$ significantly decreased adenosine levels in nicotine sensitization induced upsurge of adenosine in the striatum. Additionally, a non-significant decrease in $40 \mathrm{mg} / \mathrm{kg}$ dose can also be observed in the set of protocols. In one other study, ${ }^{67}$ Esteve et al reported that benzene-sulfonamide is a potent A2B adenosine receptor inhibitor. Further studies are warranted on the receptor level for 4-FBS to confirm its interaction with $\mathrm{A} 1$ and $\mathrm{A}_{2 \mathrm{~A}}$ adenosine receptors.

\section{Limitations}

Additionally, microdialysis studies in freely moving animals may provide more precise changes in adenosine and its metabolites, using HPLC with electrochemical detection techniques. Correlation between nicotine and druginduced changes concerning striatal dopamine may provide a clearer mechanistic picture of dopamine adenosine interaction.

\section{Conclusions}

In our study, we found that 4-FBS was able to antagonize the acquisition and expression of nicotine induces behavioral sensitization in $\mathrm{BALB} / \mathrm{c}$ mice. Moreover, adenosine level was significantly reduced by $4-\mathrm{FBS}$ at $60 \mathrm{mg} / \mathrm{kg}$. Further studies are warranted to explore the exact mechanism in the reward pathway in the specific brain areas.

\section{Acknowledgment}

We thankfully acknowledge the language editing of the manuscript by Dr. Garcia Rivas University of Yale USA.

\section{Disclosure}

The authors report no conflicts of interest in this work.

\section{References}

1. WHO. Global report on trends in prevalence of tobacco smoking; 2015. Available from: https://apps.who.int/iris/handle/10665/156262. Accessed September 20, 2019.

2. Benowitz N. Clinical pharmacology of nicotine: implications for understanding, preventing, and treating tobacco addiction. Clin Pharmacol Ther. 2008;83(4):531-541. doi:10.1038/clpt.2008.3

3. Hughes JR, Keely J, Naud S. Shape of the relapse curve and long-term abstinence among untreated smokers. Addict. 2004;99(1):29-38. doi:10.1111/j.1360-0443.2004.00540.x
4. García-Rodríguez O, Secades-Villa R, Flórez-Salamanca L, Okuda M, Liu S-M, Blanco C. Probability and predictors of relapse to smoking: results of the national epidemiologic survey on alcohol and related conditions (NESARC). Drug Alcohol Depend. 2013;132 (3):479-485. doi:10.1016/j.drugalcdep.2013.03.008

5. Steketee JD, Kalivas PW. Drug wanting: behavioral sensitization and relapse to drug-seeking behavior. Pharmacol Rev. 2011;63(2):348-365.

6. Tapper AR, McKinney SL, Nashmi R, et al. Nicotine activation of $\alpha 4 *$ receptors: sufficient for reward, tolerance, and sensitization. Science. 2004;306(5698):1029-1032. doi:10.1126/science.1099420

7. Martin-Soelch C. Neuroadaptive changes associated with smoking: structural and functional neural changes in nicotine dependence. Brain Sci. 2013;3(1):159-176. doi:10.3390/brainsci3010159

8. Picciotto MR, Addy NA, Mineur YS, Brunzell DH. It is not "either/or": activation and desensitization of nicotinic acetylcholine receptors both contribute to behaviors related to nicotine addiction and mood. Prog Neurobiol. 2008;84(4):329-342. doi:10.1016/j.pneurobio.2007.12.005

9. Goutier W, O'Connor J, Lowry JP, McCreary AC. The effect of nicotine induced behavioral sensitization on dopamine D1 receptor pharmacology: an in vivo and ex vivo study in the rat. Eur Neuropsychopharmacol. 2015;25(6):933-943. doi:10.1016/j. euroneuro.2015.02.008

10. Agboola S, McNeill A, Coleman T, Leonardi Bee J. A systematic review of the effectiveness of smoking relapse prevention interventions for abstinent smokers. Addict. 2010;105(8):1362-1380. doi:10.1111/j.1360-0443.2010.02996.x

11. Brown RM, Short JL. Adenosine A2A receptors and their role in drug addiction. J Pharm Pharmacol. 2008;60(11):1409-1430. doi:10.1211/jpp.60.11.0001

12. Ferré S, Diamond I, Goldberg S, et al. Adenosine A2A receptors in ventral striatum, hypothalamus and nociceptive circuitry: implications for drug addiction, sleep and pain. Prog Neurobiol. 2007;83 (5):332-347. doi:10.1016/j.pneurobio.2007.04.002

13. Hack SP, Christie MJ. Adaptations in adenosine signaling in drug dependence: therapeutic implications. Crit Rev Neurobiol. 2003;15:3\&4.

14. Franco R, Ferré S, Agnati L, et al. Evidence for adenosine/dopamine receptor interactions: indications for heteromerization. Neuropsychopharmacol. 2000;23(1):S50-S59. doi:10.1016/S0893-133X (00)00144-5

15. Fiorillo CD, Williams JT. Selective inhibition by adenosine of mGluR IPSPs in dopamine neurons after cocaine treatment. $J$ Neurophysiol. 2000;83(3):1307-1314. doi:10.1152/jn.2000.83.3.1307

16. Filip M, Zaniewska M, Frankowska M, Wydra K, Fuxe K. The importance of the adenosine A2A receptor-dopamine D2 receptor interaction in drug addiction. Curr Med Chem. 2012;19(3):317-355. doi: $10.2174 / 092986712803414231$

17. Shen H-Y, Canas PM, Garcia-Sanz P, et al. Adenosine A $2 A$ receptors in striatal glutamatergic terminals and GABAergic neurons oppositely modulate psychostimulant action and DARPP-32 phosphorylation. PLoS One. 2013;8(11):e80902. doi:10.1371/journal.pone.0080902

18. Fredholm BB, Irenius E, Kull B, Schulte G. Comparison of the potency of adenosine as an agonist at human adenosine receptors expressed in Chinese hamster ovary cells. Biochem Pharmacol. 2001;61(4):443-448. doi:10.1016/S0006-2952(00)00570-0

19. Latini S, Pedata F. Adenosine in the central nervous system: release mechanisms and extracellular concentrations. J Neurochem. 2001;79 (3):463-484.

20. Jastrzębska J, Nowak E, Smaga I, et al. Adenosine (A) $2 \mathrm{~A}$ receptor modulation of nicotine-induced locomotor sensitization. A pharmacological and transgenic approach. Neuropharmacol. 2014;81:318-326. doi:10.1016/j.neuropharm.2014.03.002

21. Sahraei H, Aliabadi AA, Zarrindast M-R, et al. Ascorbic acid antagonizes nicotine-induced place preference and behavioral sensitization in mice. Eur J Pharmacol. 2007;560(1):42-48. doi:10.1016/j. ejphar.2006.12.019 
22. Kayir H, Goktalay G, Yildirim M, Uzbay TI. Clozapine inhibits development and expression of nicotine-induced locomotor sensitization in rats. Synapse. 2009;63(1):15-21. doi:10.1002/syn.20576

23. Breivogel C, Jamerson B. Passion flower extract antagonizes the expression of nicotine locomotor sensitization in rats. Pharm Biol. 2012;50(10):1310-1316. doi:10.3109/13880209.2012.674535

24. Barbosa-Méndez S, Jurado $N$, Matus-Ortega $M$, Martiñon S, Heinze G, Salazar-Juárez A. Mirtazapine attenuates the expression of nicotine-induced locomotor sensitization in rats. Eur J Pharmacol. 2017;812:28-37. doi:10.1016/j.ejphar.2017.06.028

25. Knackstedt LA, LaRowe S, Mardikian P, et al. The role of cystine-glutamate exchange in nicotine dependence in rats and humans. Biol Psychiatry. 2009;65(10):841-845. doi:10.1016/j. biopsych.2008.10.040

26. Knackstedt LA, Melendez RI, Kalivas PW. Ceftriaxone restores glutamate homeostasis and prevents relapse to cocaine seeking. Biol Psychiatry. 2010;67(1):81-84. doi:10.1016/j.biopsych.2009.07.018

27. Yamamura S, Saito H, Suzuki N, et al. Effects of zonisamide on neurotransmitter release associated with inositol triphosphate receptors. Neurosci Lett. 2009;454(1):91-96. doi:10.1016/j.neulet.20 09.02 .065

28. Carta F, Supuran CT. Diuretics with carbonic anhydrase inhibitory action: a patent and literature review (2005-2013). Expert Opin Ther Pat. 2013;23(6):681-691. doi:10.1517/13543776.2013.780598

29. Aggarwal M, Kondeti B, McKenna R. Anticonvulsant/antiepileptic carbonic anhydrase inhibitors: a patent review. Expert Opin Ther Pat. 2013;23(6):717-724.

30. Krall N, Pretto F, Decurtins W, Bernardes GJ, Supuran CT, Neri D. A small-molecule drug conjugate for the treatment of carbonic anhydrase IX expressing tumors. Angew Chem Int Ed. 2014;53 (16):4231-4235. doi:10.1002/anie.201310709

31. Asiedu MN, Mejia GL, Hübner CA, Kaila K, Price TJ. Inhibition of carbonic anhydrase augments GABAA receptor-mediated analgesia via a spinal mechanism of action. J Pain. 2014;15(4):395-406. doi:10.1016/j.jpain.2014.01.001

32. Dunn KE, Marcus TF, Kim C, Schroeder JR, Vandrey R, Umbricht A. Zonisamide reduces withdrawal symptoms but does not enhance varenicline-induced smoking cessation. Nicotine Tob Res. 2015;18(5):1171-1179. doi:10.1093/ntr/ntv236

33. Sona Khan M, Trenet W, Xing N, et al. A novel sulfonamide, 4-fs, reduces ethanol drinking and physical withdrawal associated with ethanol dependence. Int J Mol Sci. 2020;21(12):4411. doi:10.3390/ ijms21124411

34. Jain R, Mukherjee K, Balhara YPS. The role of NMDA receptor antagonists in nicotine tolerance, sensitization, and physical dependence: a preclinical review. Yonsei Med J. 2008;49(2):175-188.

35. Khaldy H, León J, Escames G, Bikjdaouene L, García JJ, Acuña-Castroviejo D. Circadian rhythms of dopamine and dihydroxyphenyl acetic acid in the mouse striatum: effects of pinealectomy and of melatonin treatment. Neuroendocrinol. 2002;75(3):201-208. doi: $10.1159 / 000048238$

36. Sottofattori E, Anzaldi M, Ottonello L. HPLC determination of adenosine in human synovial fluid. $J$ Pharm Biomed Anal. 2001;24 (5-6):1143-1146. doi:10.1016/S0731-7085(00)00574-4

37. al-Rashida M, Ejaz SA, Ali S, et al. Diarylsulfonamides and their bioisosteres as dual inhibitors of alkaline phosphatase and carbonic anhydrase: structure activity relationship and molecular modelling studies. Bioorg Med Chem. 2015;23(10):2435-2444. doi:10.1016/j. bmc.2015.03.054

38. Akdag E, Kayir H, Uzbay TI. Effects of risperidone on development and expression of nicotine-induced locomotor sensitization in rats. Synapse. 2011;65(8):708-714. doi:10.1002/syn.20886

39. Goutier W, Kloeze MB, McCreary AC. The effect of varenicline on the development and expression of nicotine-induced behavioral sensitization and cross-sensitization in rats. Addict Biol. 2013;20 (2):248-258. doi:10.1111/adb.12108
40. Kalivas PW, Stewart J. Dopamine transmission in the initiation and expression of drug-and stress-induced sensitization of motor activity. Brain Res Rev. 1991;16(3):223-244. doi:10.1016/0165-0173(91) 90007-U

41. D'souza MS, Markou A. Neuronal mechanisms underlying development of nicotine dependence: implications for novel smoking-cessation treatments. Addict Sci Clin Pract. 2011;6(1):4.

42. Shepherd GM. Corticostriatal connectivity and its role in disease. Nat Rev Neurosci. 2013;14(4):278-291. doi:10.1038/nrn3469

43. Abekawa T, Ohmori T, Ito K, Koyama T. D1 dopamine receptor activation reduces extracellular glutamate and GABA concentrations in the medial prefrontal cortex. Brain Res. 2000;867(1-2):250-254. doi:10.1016/S0006-8993(00)02298-8

44. Jaber M, Robinson SW, Missale C, Caron MG. Dopamine receptors and brain function. Neuropharmacol. 1996;35(11):1503-1519. doi:10.1016/S0028-3908(96)00100-1

45. Floran B, Barajas C, Floran L, Erlij D, Aceves J. Adenosine A1 receptors control dopamine D1-dependent [3H] GABA release in slices of substantia nigra pars reticulata and motor behavior in the rat. Neurosci. 2002;115(3):743-751. doi:10.1016/S0306-4522(02) 00479-7

46. Ramos M, Goñi-Allo B, Aguirre N. Studies on the role of dopamine D1 receptors in the development and expression of MDMA-induced behavioral sensitization in rats. Psychopharmacol. 2004;177(1-2):100-110. doi:10.1007/s00213-004-1937-0

47. Cuevas-Olguin R, Esquivel-Rendon E, Vargas-Mireles $\mathrm{J}$, et al. Nicotine smoking concentrations modulate GABAergic synaptic transmission in murine medial prefrontal cortex by activation of $\alpha 7^{*}$ and $\beta 2 *$ nicotinic receptors. Eur $J$ Neurosci. 2020;51 (3):781-792. doi:10.1111/ejn.14595

48. Barker JS, Hines RM. Regulation of GABAA receptor subunit expression in substance use disorders. Inter J Mol Sci. 2020;21 (12):4445. doi:10.3390/ijms21124445

49. Filip M, Frankowska M, Zaniewska M, et al. Involvement of adenosine A2A and dopamine receptors in the locomotor and sensitizing effects of cocaine. Brain Res. 2006;1077(1):67-80. doi:10.1016/j. brainres.2006.01.038

50. Schiffmann SN, Fisone G, Moresco R, Cunha RA, Ferré S. Adenosine A2Areceptors and basal ganglia physiology. Prog Neurobiol. 2007;83(5):277-292. doi:10.1016/j.pneurobio.2007.0 5.001

51. Pinna A, Corsi C, Carta AR, Valentini V, Pedata F, Morelli M. Modification of adenosine extracellular levels and adenosine A2A receptor mRNA by dopamine denervation. Eur $J$ Pharmacol. 2002;446(1):75-82. doi:10.1016/S0014-2999(02)01818-6

52. Castañé A, Soria G, Ledent C, Maldonado R, Valverde O. Attenuation of nicotine-induced rewarding effects in A2A knockout mice. Neuropharmacol. 2006;51(3):631-640. doi:10.1016/j. neuropharm.2006.05.005

53. Gill WD, Shelton HW, Burgess KC, Brown RW. Effects of an adenosine A2A agonist on the rewarding associative properties of nicotine and neural plasticity in a rodent model of schizophrenia. J Psychopharmacol. 2020;34(1):137-144. doi:10.1177/02698811198 85917

54. Harvey J, Lacey MG. A postsynaptic interaction between dopamine D1 and NMDA receptors promotes presynaptic inhibition in the rat nucleus accumbens via adenosine release. J Neurosci. 1997;17 (14):5271-5280. doi:10.1523/JNEUROSCI.17-14-05271.1997

55. Bonci A, Malenka RC. Properties and plasticity of excitatory synapses on dopaminergic and GABAergic cells in the ventral tegmental area. J Neurosci. 1999;19(10):3723-3730. doi:10.1523/ JNEUROSCI.19-10-03723.1999

56. Bonci A, Williams JT. A common mechanism mediates long-term changes in synaptic transmission after chronic cocaine and morphine. Neuron. 1996;16(3):631-639. doi:10.1016/S08966273(00)80082-3 
57. Svenningsson P, Le Moine C, Aubert I, Burbaud P, Fredholm B, Bloch B. Cellular distribution of adenosine A2A receptor mRNA in the primate striatum. J Comp Neurol. 1998;399(2):229-240. doi:10.1002/(SICI)1096-9861(19980921)399:2<229::AID-CNE6>3. $0 . \mathrm{CO} ; 2-2$

58. Ferré S, Fuxe K, Fredholm BB, Morelli M, Popoli P. Adenosinedopamine receptor-receptor interactions as an integrative mechanism in the basal ganglia. Trends Neurosci. 1997;20(10):482-487. doi:10.1016/S0166-2236(97)01096-5

59. Dawson TM, Barone P, Sidhu A, Wamsley J, Chase T. The D1 dopamine receptor in the rat brain: quantitative autoradiographic localization using an iodinated ligand. Neurosci. 1988;26 (1):83-100. doi:10.1016/0306-4522(88)90129-7

60. Fastbom J, Pazos A, Palacios J. The distribution of adenosine A1 receptors and 5'-nucleotidase in the brain of some commonly used experimental animals. Neurosci. 1987;22(3):813-826. doi:10.1016/ 0306-4522(87)92961-7

61. Ferré S, Torvinen M, Antoniou K, et al. Adenosine A1 receptor-mediated modulation of dopamine D1 receptors in stably cotransfected fibroblast cells. J Biol Chem. 1998;273(8):4718-4724. doi:10.1074/jbc. 273.8 .4718

62. Ferré S, Popoli P, Giménez-Llort L, et al. Postsynaptic antagonistic interaction between adenosine A1 and dopamine D1 receptors. Neuroreport. 1994;6(1):73-76. doi:10.1097/00001756-19941230000020
63. Sweeney MI. Neuroprotective effects of adenosine in cerebral ischemia: window of opportunity. Neurosci Biobehav Rev. 1997;21 (2):207-217. doi:10.1016/S0149-7634(96)00011-5

64. Von Lubitz DK, Paul IA, Ji X-D, Carter M, Jacobson KA. Chronic adenosine A1 receptor agonist and antagonist: effect on receptor density and N-methyl-D-aspartate induced seizures in mice. Eur J Pharmacol. 1994;253(1-2):95-99. doi:10.1016/0014-2999(94)90762-5

65. de Mendonça A, Sebastião AM, Ribeiro JA. Adenosine: does it have a neuroprotective role after all? Brain Res Rev. 2000;33(2-3):258-274. doi:10.1016/S0165-0173(00)00033-3

66. Poleszak E, Malec D. Adenosine receptor ligands and cocaine in conditioned place preference (CPP) test in rats. Pol J Pharmacol. 2002;54(2):119-126.

67. Esteve C, Nueda A, Díaz JL, et al. New pyrrolopyrimidin-6-yl benzenesulfonamides: potent $\mathrm{A} 2 \mathrm{~B}$ adenosine receptor antagonists. Bioorg Med Chem Lett. 2006;16(14):3642-3645. doi:10.1016/j. bmcl.2006.04.074

\section{Publish your work in this journal}

Drug Design, Development and Therapy is an international, peerreviewed open-access journal that spans the spectrum of drug design and development through to clinical applications. Clinical outcomes, patient safety, and programs for the development and effective, safe, and sustained use of medicines are a feature of the journal, which has also been accepted for indexing on PubMed Central. The manuscript management system is completely online and includes a very quick and fair peer-review system, which is all easy to use. Visit http://www. dovepress.com/testimonials.php to read real quotes from published authors. 